DOI: 10.4322/978-65-89910-16-9-03

\title{
A GESTÃo ESTRATÉGICA DE VENDAS COMO FERRAMENTA DE SUCESSO AO DESEMPENHO ORGANIZACIONAL: estudo de caso de uma micro empresa
}

\author{
Fernanda Raquel Gomes de Lima ${ }^{12}$ \\ Jaqueline Pimentel ${ }^{13}$ \\ João Victor Ferreira Santos ${ }^{14}$ \\ Letícia Dalete Ferreira Rodrigues ${ }^{15}$ \\ Valdinéia Guedes dos Santos ${ }^{16}$
}

\footnotetext{
12 Discente do curso de Administração da Faculdade Edufor. E-mail: flima753@yahoo.com.br

${ }^{13}$ Docente da Faculdade Edufor. E-mail: jaqueline.pimentel@edufor.edu.br 14 Discente do curso de Administração da Faculdade Edufor. E-mail: Irvictorferreira@outlook.com

15 Discente do curso de Administração da Faculdade Edufor. E-mail: leticiadalet@hotmail.com

16 Discente do curso de Administração da Faculdade Edufor. E-mail: neia.guedes55@gmail.com
} 


\section{RESUMO}

Os conhecimentos que relacionam 0 desempenho organizacional e as técnicas de vendas vêm evidenciando a relevância da estrutura do processo de vendas, objetivando aumentar a lucratividade. É nesse sentido que, a gestão estratégica atinge sua otimização ao identificar o poder almejado quando se tem uma empresa bem estruturada, com estratégias definidas e um gerenciamento da equipe de vendas que propicie elevar o grau de produtividade de sua equipe, através de estímulos e qualificando a capacitação necessária para que se alcancem os objetivos traçados. Partindo desse princípio, esta pesquisa tem a pretensão de relatar o processo de vendas como ferramenta para se ganhar vantagem competitiva no mercado, e desse modo, contribuir para o melhor desempenho organizacional, inclusive com redução significativa de estoques. Além disso, o caminho para a realização de vendas vem sofrendo influências significativas no que tange às ações para alavancar as receitas, com o desenvolvimento do processo de atendimento e a evolução da equipe de vendas, para tornar visível o quão importante se torna a capacitação, a coesão e a motivação da mesma para que as empresas alcancem o resultado esperado. Assim, o processo de vendas assume maior importância dentro das organizações, com a intenção de construir e manter em longo prazo o melhor desempenho no que tange à quantidade vendida de produtos e serviços, especialmente para o objeto deste estudo: a empresa "azul" . O estudo ainda aborda a conceituação dos principais fatores para que se alcance sucesso nas vendas, sobretudo, todos esses fatores não são 
suficientes para alavancar as vendas de uma empresa se não contarem com outros três elementos indispensáveis para o sucesso das vendas. É importante também, deixar ciente que 0 processo de vendas adequadamente estruturado, alinhado à uma comunicação significativa com os colaboradores que atuam nas organizações, desempenham um papel vital estratégico nas organizações orientadas para resultados que vão impactar diretamente o desempenho e a lucratividade das empresas.

Palavras-chave: Desempenho organizacional. Técnicas de vendas. Lucratividade. Vantagem competitiva; Atendimento.

\section{ABSTRACT}

The knowledge that relates the organizational performance and the sales techniques purchased showing a structure of the structure of the sales process aiming to increase profitability. It is in this sense that a strategic strategic management optimizes it when identifying the desired power when having a well-structured company, with defined and sales team management that provides a high level of productivity of its team through stimuli and qualifying a necessary qualification to achieve the objectives set. Based on this principle, this research aims to report the sales process as a tool to gain competitive advantage in the market and thus contribute to better organizational performance, including reducing inventories. In addition, the path to making sales has suffered significant influences in terms of actions to leverage as revenues, with the development of the service process and the evolution of the sales team, to make 
visible how important training becomes, its cohesion and motivation for companies to achieve the expected result. Thus, the sales process takes on greater importance within organizations, with the intention of building and maintaining the best performance in the long term with regard to the quantity of products and services sold, especially for the object of this study blue company hey do not have three other elements that are indispensable for the success of sales. It is also important to be aware that the planned sales process, aligned with adequate communication with employees working in associations, play a vital strategic role in results-oriented organizations that will directly impact companies' performance and profitability.

Keywords: Organizational performance; Sales techniques. Profitability. Competitive advantage. Attendance.

\section{INTRODUÇÃO}

O tema desenvolvido neste trabalho trata da Gestão de Vendas, com o objetivo de demonstrar sua importância como papel fundamental no estabelecimento e desenvolvimento de uma empresa comercial, bem como estabelecer a relevância dessa gestão para que a empresa se mantenha bem avaliada no mercado. Observa-se o cenário de empresas comerciais, e 
identifica-se a força que tem uma organização bem estruturada, com uma boa definição de estratégias e gerenciamento da equipe de vendas, visando à capacitação de novos clientes e manutenção dos mesmos, oferecendo produtos de qualidade e preços acessíveis.

O gerenciamento da equipe de vendas, contando com uma liderança presente, bem como de implantação de normas e procedimentos para que se mantenha no mercado de forma competitiva, tem sido fatores determinantes para que empresas tenham se estabelecido. A conquista de destaque no mercado tem necessitado da diferenciação oferecida pela empresa, não só no tocante a preços e qualidade dos produtos oferecidos, mas também pelo engajamento de seus funcionários para oferecer um atendimento de qualidade.

$O$ assunto a ser discorrido, vem destacar pontos que se consideram relevantes, especificamente para as micro empresas, tal como a empresa "azul", para que permaneçam ao longo dos anos com uma boa avaliação feita por seus clientes em todo o âmbito da empresa. Veremos, portanto, o desenvolvimento do processo de 
atendimento e a evolução da equipe de vendas, para que possamos entender o quão importante se torna a necessidade da prática de treinamentos para que sejam reforçadas as técnicas de negociação; de averiguar o grau de coesão que existe na equipe, que se estabelece quando cada colaborador, independentemente de seu cargo, entende que faz parte de um todo e percorre na mesma direção em prol de um mesmo objetivo e, em consonância a tudo isso, não perder o espírito motivacional da equipe, que facilita a conquista de suas metas traçadas para alcançar o resultado esperado.

Desta forma, estudaremos a seguir, as causas decisivas para o sucesso na Gestão de Vendas. Para alcançarmos o resultado do estudo desenvolvido, foram feitas pesquisas com abordagem qualitativa, em que tivemos uma percepção dos fatores que contribuem para a eficiência na Gestão de vendas e os caminhos percorridos para tais fatos.

Diante disso, o presente artigo tem como objetivo geral: avaliar o item vendas como recurso estratégico para obter sucesso no desempenho organizacional. 
Procurando alcançar o objetivo geral deste estudo, pretende-se ressaltar os objetivos específicos, que são: identificar na literatura científica as principais características e funcionalidades da venda e os perfis dos vendedores; verificar a trajetória necessária a ser explorada por indivíduos participantes de uma equipe de vendas, sendo estes gestores ou pessoas subordinadas; detectar os principais fatores de sucesso nas vendas; identificar prováveis mudanças e avanços organizacionais nas vendas, a partir da implementação do processo de coaching;

Essa pesquisa está dividida em quatro capítulos. $\mathrm{O}$ primeiro é a introdução, que insere o leitor ao assunto temático. O segundo, é o referencial teórico, em que será tratado a importância da relação gestor-equipe com ênfase na mudança tanto pessoal quanto na cultura organizacional, os fatores primordiais para o sucesso das vendas e logo em seguida, o ápice deste vigente artigo a concretização da gestão estratégica de vendas. O terceiro capítulo é a metodologia que explicita o seu caráter bibliográfico e o estudo de caso que caracteriza a empresa pesquisada com seu levantamento de 
resultados. E por fim, completando a estrutura do artigo com a conclusão, que traduz de forma singular como uma equipe de vendas bem orientada e estruturada pode ser uma alternativa estratégica.

\section{FUNDAMENTAÇÃO TEÓRICA}

A venda é um processo que necessita de muito planejamento e preparação, principalmente se o seu processo depende de uma equipe de vendas. Dessa maneira, alguns pontos são essenciais para o seu sucesso.

\subsection{O Papel do supervisor de equipe como parte} fundamental das vendas

Para Kotler (1998) a gestão de vendas é a centralização dos atos de recrutamento e seleção, treinamento, direção, motivação e avaliação da equipe. A ação de forma sistemática, ou seja, a planificação para o impulso das vendas são os objetivos, as estratégias, a estrutura, o tamanho e a remuneração. Já o desenvolvimento da força de vendas seria o treinamento, 
as habilidades de negociação e a construção de relacionamentos. Sendo assim, entende-se que a função de um gestor de equipe de vendas torna-se fundamental para que se alcance o sucesso pretendido, uma vez que o mesmo não é simplesmente um indivíduo com a nomenclatura de chefia, mas sim um líder com as competências necessárias para auxiliar e apoiar a equipe em todo o processo da venda.

De acordo com sua afirmação, Kotler nos leva a pensar que o supervisor de uma equipe tem como característica principal elevar o grau de produtividade de sua equipe através de estímulo e propiciando a capacitação necessária para que se alcancem os objetivos traçados pela diretoria da empresa, bem como estar presente em todos os procedimentos de sua equipe, avaliando se os resultados foram alcançados, e se não obtivendo, saber identificar os problemas que impossibilitaram e os reflexos causados por eles.

Neste caso, este indivíduo deve ser um bom ouvinte, respeitando e analisando a opinião de cada participante do referido processo, e principalmente deve ser conhecedor dos negócios da sua empresa, mantendo-se 
atualizado constantemente. Sendo assim, a título de estímulo a sua equipe, a busca por constante atualização e prática de vendas, deve ser uma situação observada no dia a dia de seu supervisor, pois administrar uma equipe de vendas requer habilidades tais quais de um simples vendedor.

\begin{abstract}
A associação americana de marketing, através de seu comitê de definição, definiu administração de vendas como "planejamento, direção e controle de venda pessoal, incluindo recrutamento, seleção, treinamento, providencias de recursos, delegação, determinação de rotas, supervisão, pagamento e motivação, à medida que essas tarefas se apliquem à força de vendas". Na verdade, hoje administração de vendas não somente trata da força de vendas, mas também se ocupa com a inovação, pesquisa, planejamento, orçamento, preço, canais, promoção, produção e de até localização de fábricas (LAS CASAS, 2006, p.409).
\end{abstract}

De acordo com esta citação, Las Casas (2006) nos

leva a entender que o gerente de vendas deverá definir estratégias, de forma que consiga o máximo de seus vendedores. Desta forma, o mesmo deverá elaborar planos de vendas e traçar estratégias, bem como supervisionar a execução de todas as ações. Cabe a ele também, o recrutamento e o treinamento da equipe, para 
que atue em harmonia, através de procedimentos padronizados, visando o uso de uma mesma linguagem, e assim obtenha uma comunicação clara entre os membros da equipe, assim como objetividade na relação cliente/empresa.

Isso inclui também a busca por produtos com qualidade e preços cada vez mais acessíveis, através de novas fábricas e novos fornecedores, visualizando também meios e canais para promover a propagação das novidades a serem alcançadas pelos clientes. Outro fator importante a ser observado nas ações do gerente de vendas, é que ele deve estar apto a vender também, muito embora possa reservar a si a responsabilidade de fechar os grandes negócios, de acordo com a citação:

Mesmo os mais habilidosos vendedores enferrujam-se sem uma prática regular. Você não pode querer liderar e motivar os outros se não consegue mostrar a equipe como fazer melhor (THORN, 1992 p.3).

Ou seja, o supervisor de vendas servirá de modelo e influência para que sua equipe se mantenha incitada na busca de melhores negócios para a empresa e para a realização pessoal de cada membro da equipe. A partir do que foi mencionado sobre Kotler (1998) observa-se que 
para o bom desempenho das atividades do gestor de vendas, o mesmo deverá conhecer todos os trâmites da empresa na qual atua, para que possa identificar as dificuldades e empecilhos que sua equipe encontra no dia a dia e desenvolva melhorias que possam solucioná-las.

As expectativas geradas a respeito de sua equipe dependerão de seu nível de envolvimento com a mesma, da visão dos problemas e impactos causados por eles, e para isso, torna-se necessário que haja uma relação de retorno entre equipe e gestor, pois dela dependerá todo o desenvolver da administração de vendas na empresa. Considerando a importância deste, pode-se fazer a analogia de um supervisor ao coach, um profissional que frequentemente trabalha com o colaborador (coachee). $O$ Coaching oferece estrutura e o processo necessário às verdadeiras transformações, sendo considerado como uma ferramenta importante na gestão empresarial, pois traz à tona o que há de melhor nas pessoas e visa liberar o potencial de uma pessoa para sua performance, ajudando-a a aprender em vez de ensiná-la.

Chiavenato (2002) trata o coaching como um caminho para estimular mudanças internas nas empresas 
para que, assim, possam expor de forma salutar, tanto as inovações, quanto o que as organizações divulgam. Às modificações intrínsecas são atribuídas: os costumes, os valores, as condutas, as ações e os papéis reconhecidos pelas pessoas, além das relações mútuas e da cultura organizacional. O processo coaching de Chiavenato, ilustrado na figura Figura 1, começa pelo levantamento do perfil do colaborador.

Figura 01 - Etapas da abordagem de coaching

\begin{tabular}{|c|c|c|c|c|}
\hline Levantamento & \multicolumn{4}{|c|}{ Seções de Coaching } \\
\hline $\begin{array}{c}\text { Relatório de } \\
\text { Avaliação }\end{array}$ & $\begin{array}{l}\text { Criar } \\
\text { Ambiente }\end{array}$ & $\begin{array}{l}\text { Ouvir o } \\
\text { Aprendiz }\end{array}$ & $\begin{array}{c}\text { Fazer } \\
\text { Perguntas }\end{array}$ & $\begin{array}{c}\text { Proporcionar } \\
\text { Feedback }\end{array}$ \\
\hline $\begin{array}{l}\text { Dicas: } \\
\text { - Revisão do } \\
\text { currículo pessoal } \\
\text { e profissional; } \\
\text { - Auto-avaliação; } \\
\text { - Avaliação da } \\
\text { chefia, colegas e } \\
\text { subordinados. }\end{array}$ & $\begin{array}{l}\text { Dicas: } \\
\text { - Apoiar o } \\
\text { desenvolvimento } \\
\text { e a eficácia do } \\
\text { aconselhado; } \\
\text { - Focalizar o } \\
\text { aumento da } \\
\text { eficácia ou } \\
\text { determinar outra } \\
\text { visão. }\end{array}$ & $\begin{array}{l}\text { Dicas: } \\
\text { - Evite } \\
\text { interrupções; } \\
\text { - Ouça e } \\
\text { incentive } \\
\text { comentários; } \\
\text { - Troque idéias; } \\
\text { - Reflita. }\end{array}$ & $\begin{array}{l}\text { Dicas: } \\
\text { - Ajude o } \\
\text { aconselhado a } \\
\text { alcançar os } \\
\text { objetivos; } \\
\text { - Localiza } \\
\text { dúvidas; } \\
\text { - Abra } \\
\text { possibilidades; } \\
\text { - Explore } \\
\text { assuntos. }\end{array}$ & $\begin{array}{l}\text { Dicas: } \\
\text { - Auxilie o } \\
\text { aconselhado a } \\
\text { identificar e } \\
\text { superar } \\
\text { dificuldades; } \\
\text { - Focalize, } \\
\text { esclareça e } \\
\text { priorize o que } \\
\text { necessita ser } \\
\text { feito. }\end{array}$ \\
\hline
\end{tabular}

Fonte: adaptado de Chiavenato (2002).

Esta tabela acima é referente às seções de coaching e consiste na análise do currículo pessoal e profissional deste funcionário, seus propósitos profissionais, o que percebe e espera do coaching. Conclui a resenha do perfil deste com uma autorreflexão, a conjectura da chefia e 
colegas, suas ações, condutas e comunicação interpessoal. Das considerações do perfil é extraído um esclarecimento de avaliação que sintetiza como estão o vigor mental, físico e emocional daquele em questão. Em diante, segue o processo com as seções de coaching, encontros entre o coach e o aconselhado, que proporciona muitos momentos de discussão, novos testes, feedbacks específicos, planos de ações com foco na execução e estabelecimento de tempo para cumpri-las. As fases para ocorrer seções de coaching satisfatórias são: criar um ambiente favorável às reuniões; ouvir atentamente 0 aconselhado; fazer perguntas ao aconselhado; proporcionar feedbacks úteis.

\subsection{Principais fatores para que se alcance sucesso em vendas}

Atualmente, existe uma variedade enorme de métodos, técnicas e abordagens destinadas ao empresário que procura melhorar seu desempenho em vendas. Contudo, o desafio de saber o que realmente é efetivo e o que não funciona ainda permanece para muitos deles. Somente estudando permanentemente o seu 
público e produto é que se se torna possível contribuir para uma melhor compreensão do que o empresário pode realizar a partir de escolhas conscientes, a fim de que a gestão de vendas seja personalizada para seu negócio.

Nesse sentido, entre os fatores citados por BITTEL (1982), que justificam como essenciais para que se alcance o objetivo de ter sucesso nas vendas, elenca-se - Planejamento, Organização, Capacitação e a Motivação. De acordo com esse autor, é no planejamento que as ideias são remodeladas em ação.

Portanto, para que seja atingido resultados satisfatórios, precisamos primeiramente, definir quais os objetivos e quais as estratégias que serão definidas, para então alcançarmos tais objetivos. O planejamento estratégico é importante para toda empresa que pretende ter desenvolvimento e crescimento, não obstante do seu seguimento de atividade. No entanto, alguns setores são mais obstinados em relação às atividades desenvolvidas ou ao ramo de atuação. Neste caso, o planejamento estratégico é uma condição para sobreviver. Como exemplo, temos as micro empresas, como as papelarias, cujo mercado competitivo necessitam de decisões 
estratégicas eficientes para não perder território em um segmento que diariamente ganha mais opositores.

Ao começar a planejar a equipe a partir dos objetivos de vendas, é muito importante identificar o perfil e a função dos vendedores, a fim de que a empresa possa planejar as informações, conhecimentos, habilidades e atitudes necessárias à equipe, desenvolvendo assim, a compreensão do elo existente entre o vendedor, a empresa e o cliente no êxito das vendas. $O$ perfil e função dos vendedores são ilustrados, respectivamente, pelas figuras 2 e 3 :

Figura 02 - Tipos de vendas e perfis de vendedor

\begin{tabular}{|c|c|}
\hline \multicolumn{2}{|c|}{ TIPOS DE VENDAS E PERFIS DE VENDEDOR } \\
\hline $\begin{array}{l}\text { * VENDA CONSULTIVA: } \\
\text { - Venda com grau de sofisticação técnica, o vendedor atua mais } \\
\text { como consultor para resolver os problemas do cliente. } \\
\text { - Demoram a ser fechadas e dependem de sólido conhecimento do } \\
\text { vendedor. } \\
\text { - Prestação de serviços em que o vendedor conhece mais do que o } \\
\text { cliente. } \\
\text { - Exemplos: sistemas de gestão, redes de informática, automação } \\
\text { industrial. } \\
\text { * VENDA DE RELACIONAMENTO: } \\
\text { - Vendas repetidas, regulares, que ocorrem entre empresas ou } \\
\text { mesmo ao consumidor final, mas por longos períodos. } \\
\text { - O vendedor costuma conhecer pelo nome a maioria das pessoas } \\
\text { da empresa, da recepção ao diretor. } \\
\text { - Exemplos: commodities, componentes e insumos industriais de } \\
\text { uso constante, fornecimento de matérias-primas diversas. }\end{array}$ & $\begin{array}{l}\text { * VENDA DE FECHAMENTO/FACE A FACE: } \\
\text { - Ao vender pessoalmente, os clientes formam impressões sobre a } \\
\text { aparência do vendedor e a organização que representa. Ele deve } \\
\text { estar munido dos materiais de apoio para explicar aos clientes } \\
\text { sobre seus produtos. } \\
\text { - Também conhecida por venda de alto impacto, caracteriza-se por } \\
\text { contatos relativamente curtos, com forte apelo emocional e boa } \\
\text { argumentação. } \\
\text { - Exemplos: venda em lojas, magazines e de porta em porta. } \\
\text { * VENDA DE ESTOQUE: } \\
\text { - É aquela feita em estabelecimentos nos quais as pessoas entram } \\
\text { para fazer uma compra rápida e sem necessidade de muita } \\
\text { orientação. } \\
\text { - Exige vendedores com agilidade, bom conhecimento do estoque } \\
\text { e simpatia no trato com clientes são ideais nesse tipo de venda. } \\
\text { - Exemplos: farmácias, padarias, papelarias. }\end{array}$ \\
\hline
\end{tabular}

Fonte: Mercado e vendas. Sebrae, 2017. 
Figura 03 - Funções do profissional de vendas

\begin{tabular}{|l|l|}
\hline \multicolumn{2}{|c|}{ Funções do Profissional de Vendas } \\
\hline Capacitar-se & $\begin{array}{l}\text { Estudar os clientes, os produtos/serviços, o mercado em que atua e exercitar } \\
\text { a argumentação de vendas }\end{array}$ \\
\hline Prospectar Mercados & $\begin{array}{l}\text { Pesquisar fontes de clientes potenciais, visitar clientes, telefonar para clientes } \\
\text { e buscar novos mercados }\end{array}$ \\
\hline Criar Oportunidades & $\begin{array}{l}\text { Abordar, explicar e demonstrar serviços e produtos, apresentar } \\
\text { produtos/serviços envolver o cliente }\end{array}$ \\
\hline Desenvolver Relações & $\begin{array}{l}\text { Organizar-se, acompanhar o cliente, auxiliar o cliente a decidir e apoiar o } \\
\text { cliente em suas escolhas }\end{array}$ \\
\hline Manter Vínculos & $\begin{array}{l}\text { Atualizar-se sobre o que vende, compreender os problemas do cliente, } \\
\text { administrar relações e oferecer novas soluções }\end{array}$ \\
\hline Fidelizar Clientes & $\begin{array}{l}\text { Surpreender, resolver problemas mais rápido do que o cliente espera, } \\
\text { antecipar-se às necessidades, pensar como o cliente }\end{array}$ \\
\hline
\end{tabular}

Fonte: Mercado e vendas. Sebrae, 2017.

Outro fator importante citado por BITTEL (1982), é a Organização, qualidade esta que permite um ordenamento eficaz do trabalho. Ele defende que a delegação é um fator essencial dentro da organização, de forma que, determina, agrupa e designa as atividades e as atribui a determinadas pessoas e posições dentro da equipe. Sendo assim, a organização estabelece critérios de desenvolvimento para que a equipe de vendas conclua suas tarefas da melhor forma possível.

A capacitação não deve ser desconsiderada entre os fatores relevantes para que se alcance sucesso nas vendas de uma empresa. Pois, é nela que a equipe toma conhecimento e atualiza-se sobre todas as tendências do mercado em que a mesma atua. Sendo assim, é necessário a prática de treinamentos para que sejam 
reforçadas as técnicas de negociação e a familiarização com novos produtos, para que assim, atinja satisfatoriamente o agente desse sucesso pretendido, que é o relacionamento com o cliente. Consoante a isso, menciona-se:

É de fundamental importância que o alcance dos objetivos e quotas estabelecidas esteja vinculado ao plano de remuneração, de forma que seja montado um plano de incentivo completo. [...] como o vendedor busca maximizar a sua receita, ele irá trabalhar na direção do alcance dos objetivos estabelecidos pela empresa, caso estejam bem formulados e baseados em uma análise completa. Assim, ocorrerá um alinhamento total da estratégia da empresa com a estratégia do vendedor. De fato, um plano de incentivo bem feito (análise da função vendas determinação das quotas e objetivos- plano de remuneração) diminui os custos de supervisão e controle, além de fazer convergir os objetivos da empresa e do vendedor (CASTRO; NEVES, 2012, p.86).

Em consonância a citação acima, relaciona-se também a motivação, instrumento imprescindível na atuação da equipe, pois sem esse aspecto, dificilmente haverá o comprometimento necessário por parte dos membros da equipe. E por ser de cunho íntimo e pessoal, cada indivíduo tem as suas próprias motivações, quer 
sejam remunerações financeiras ou não. Por isto, cabe ao gestor, perpetuar esse importante quesito na equipe, através de um bom relacionamento com cada membro atuante, conhecendo as necessidades, particularidades de cada um, criando situações que propiciem a conquista de suas metas, de forma que possa impulsioná-los e motivá-los cada vez mais na execução de seus trabalhos.

De acordo com Futreel (2003), para que se atinja sucesso nas vendas, o vendedor necessita possuir algumas características. Entre elas, podemos citar o amor à sua profissão, aptidão para o trabalho e necessidade pessoal de sucesso profissional, além de um afetuoso interesse em compreender a necessidade do cliente. $O$ autor ressalta também, a necessidade de capacitação e treino para os desafios, tornando-se competente para desenvolver sua função ao longo do dia na empresa, pois possuindo os requisitos apresentados anteriormente, terá capacidade de fazer uma abordagem mais iminente ao sucesso, o que resultará também em uma relação de confiança e amizade que implicará na decisão final da venda. 


\subsection{Concretização do trabalho da gestão de vendas - agindo para fidelizar o cliente}

Gestão estratégica de vendas é o processo de tomada de decisão que conduz as ações da empresa ao longo do tempo, ponderando sua relação com o âmbito organizacional no qual está inserida. Para ser decisivo, ele deve ser planificado, treinável e avaliado, a fim de orientar o comportamento organizacional a caminho de seus objetivos.

Desta forma, se utiliza da organização de metas através do planejamento, liderança e treinamento, que constitui a Gestão de Vendas. A mesma conduz toda a força de venda de uma empresa, inclusive todas as atividades ligadas a esta área, tais como marketing, publicidade, distribuição, preços e produtos. No entanto, todos os itens elencados anteriormente não conseguirão alavancar as vendas de uma empresa se não contarem com outros três elementos indispensáveis para reter e fidelizar seus clientes: qualidade dos produtos, preço dos produtos e atendimento ao cliente. 


\subsubsection{Qualidade dos produtos}

Com o crescimento da competição dos produtos no mercado, buscam-se estratégias para que se mantenha no mercado a qualidade dos produtos que serão apresentados aos clientes. Segundo Miranda o conceito básico de qualidade é a ausência de defeitos e adequação ao uso (Miranda 1994). Para isto, as empresas deverão buscar um padrão de qualidade que vise atender a necessidade do cliente e a total satisfação deste. Uma vez satisfeito, a imagem do estabelecimento estará fixada de forma positiva e será repassada aos demais indivíduos dos grupos sociais deste cliente.

De acordo com Slack et al (2008) existe uma evolução na conscientização de que bens e serviços de alta qualidade podem trazer à organização uma considerável vantagem competitiva, já que uma boa qualidade reduz custos de reparação, refugo, devoluções e gera consumidores satisfeitos. A qualidade dos produtos evita desperdícios desnecessários com retrabalhos, produtos com defeitos, minimizando erros e o principal, reduz a insatisfação dos clientes, buscando 0 encantamento da clientela. 


\subsubsection{Preços dos produtos}

A definição dos valores a serem cobrados pelos produtos é um fator que requer dedicação para execução, devendo-se levar em consideração a necessidade de cobertura dos custos, mas também a fidelização do cliente através de preços competitivos. Para os gestores, o preço dos produtos é importante, já que é ele quem coloca a empresa dentro do mercado competitivo, que está cada vez mais acirrado.

De acordo com Wernke (2005, p.147), para a sobrevivência e crescimento de uma empresa, é de fundamental importância uma adequada precificação da venda, a pesar do porte ou área de atuação. A partir disso, cria-se uma política de preços, onde as organizações têm como objetivo realizar planejamentos e minimizar futuras incertezas, sem prejudicar a lucratividade diante da concorrência e assim atingir o sucesso da empresa. Já para o consumidor, torna-se fundamental, ao passo que é agente decisivo no momento da compra do produto e uma provável fidelização dos mesmos.

$O$ valor cobrado atinge diretamente a imagem que a empresa terá por parte de seus clientes, pois a partir daí 
os mesmos poderão ou não ter a credibilidade e confiança de que negociarão com uma instituição justa e íntegra e que não pretende explorá-los.

\subsection{Atendimento ao cliente - tratar bem ou atender bem?}

A qualidade no atendimento passa a ser fator de sobrevivência e tem por objetivo fazer com que as empresas alcancem 0 padrão de excelência e credibilidade com os clientes atuais e possíveis novos, atendendo as necessidades de seus clientes, garantindo os mesmos até a pós-venda. Uma organização deve considerar "cliente" todo aquele que frequenta, consumindo quaisquer de seus serviços, sofrendo qualquer tipo de impacto ou influência ou mantendo qualquer tipo de contato com pessoa ou setor da empresa (Mello et al, 2009).

O ápice da gestão de vendas concentra-se de forma especial no atendimento ao cliente. A busca neste ponto deve ser o suprimento da necessidade do indivíduo, quer seja no ato da compra ou em qualquer outra situação pósvenda, como possíveis reclamações, devoluções ou troca 
de mercadoria. Portanto, são essas oportunidades que estreitarão os laços do relacionamento do cliente com a equipe de vendas, de onde decorrerão outras negociações, tanto com este atual cliente, como com outros que serão impactados com a apresentação positiva inicial da empresa.

Quando se fala em atender bem, não significa que é o mesmo que recepcionar bem. Porém, os dois procedimentos andam lado a lado, pois todo cliente quer ser tratado como único, de uma forma especial.

Quadro 01 - Tratamento X Atendimento

\begin{tabular}{|c|c|}
\hline Tratamento & Atendimento \\
\hline $\begin{array}{l}\text { Refere-se simplesmente } \\
\text { aos aspectos relacionados }\end{array}$ & eito ao \\
\hline $\begin{array}{l}\text { ao tratamento gentil e } \\
\text { cordial que naturalmente }\end{array}$ & $\begin{array}{l}\text { por um tratamento cordial, como } \\
\text { também com a prontidão da empresa }\end{array}$ \\
\hline $\begin{array}{l}\text { se espera receber no } \\
\text { atendimento de todos os } \\
\text { funcionários de qualquer } \\
\text { empresa. }\end{array}$ & $\begin{array}{l}\text { em estar disponível às nossas } \\
\text { solicitações e demandas, com } \\
\text { produtos ou serviços de qualidade, } \\
\text { em um ambiente limpo e agradável. }\end{array}$ \\
\hline
\end{tabular}

Fonte: Mercado e vendas. Sebrae, 2017.

O bom atendimento é o tradutor dos anseios apresentados pelo cliente, pois será através dele que se terá conhecimento das necessidades e opiniões a respeito do trabalho desenvolvido pela equipe de vendas e de todos os departamentos da empresa. Em suma, o 
que se pode concluir, é que deve ser afirmado diante do cliente o conhecimento de todos os processos, visando promover resultados positivos na imagem repassada ao cliente sobre a composição preços, qualidade e atendimento na finalização e concretização da venda.

\section{METODOLOGIA}

A presente pesquisa foi elaborada numa empresa de papelaria de pequeno porte e não houve autorização da alta direção da empresa para divulgação do nome, devendo, portanto, ser mantido o sigilo, portanto a chamaremos pelo nome fictício de Empresa "Azul".

A abordagem metodológica adotada neste projeto caracteriza-se por ser um "estudo de caso". Para Miguel (2010) qualquer pesquisa que apresente características de uma investigação acerca de um determinado recente fenômeno acontecido dentro de um cenário diário, e com o objetivo principal de reproduzi-lo, é estudo de caso concreto. É nesse cenário que a empresa "Azul" está inserida, pois descreve a especificidade do seu seguimento comercial acerca das vendas e o 
direcionamento estratégico nesse setor que irá agregar valor ao produto, proporcionando um resultado memorável na busca da satisfação do cliente e na construção de uma imagem competitiva.

Quanto aos fins, a pesquisa é exploratória, aplicada e descritiva. Exploratória porque a organização possui um grau de informalidade, sendo necessário investigar a sua realidade a fim de obter os dados necessários para a elaboração do planejamento.

De acordo Gil (apud Silva) a pesquisa exploratória:

Visa proporcionar maior familiaridade com o problema com vistas a torná-lo explícito ou a construir hipóteses. Envolve levantamento bibliográfico; entrevistas com pessoas que tiveram experiências práticas com o problema pesquisado; análise de exemplos que estimulem a compreensão (GIL apud SILVA e MENEZES, 2001, p. 21). Quanto aos meios podemos afirmar que é um estudo de caso, uma vez que Vergara (2000) diz que:

(...) estudo de caso é o circunscrito a uma ou poucas unidades, entendidas essa como uma pessoa, uma família, um produto, uma empresa, um órgão público, uma comunidade ou mesmo um país. Tem caráter de profundidade e detalhamento (VERGARA, 2000, P. 49). 
Nesse contexto, este artigo busca ressaltar o caso desta papelaria, identificando os fatores de sucesso de uma equipe de vendas e apresentando, para isso, as definições de vendas e os diversos tipos de vendedores.

\subsection{Estudo de caso da empresa "Azul"}

A empresa "Azul", iniciou suas atividades em 2001, com o nome fantasia "Azul", tem como missão proporcionar aos clientes os produtos de qualidade além de um atendimento singularizado, superando todas as expectativas do mercado e solidificando a imagem de uma empresa de respeito e honestidade; consoante a isso, ressaltar sua visão - ser a melhor opção para nossos clientes, garantindo uma variedade de produtos e serviços de qualidade e transparência; além de construir valores ser uma família que prioriza a dignidade, fidelidade, honestidade, amizade e respeito.

$\mathrm{Na}$ ocasião o proprietário, tendo adquirido um imóvel, com o objetivo de empreender, iniciou suas vendas apenas com materiais escolares e alguns produtos para escritório. 
Com o passar dos anos, a gama de produtos foi aumentando, a partir da visualização de necessidades apresentadas pelos clientes. Hoje, tendo mais de 18 anos de tradição e de bons serviços, acompanhando as tendências, inovações mercadológicas voltadas ao atendimento dessas necessidades, a empresa "Azul" aumenta suas variedades, oferecendo brinquedos $\mathrm{e}$ artigos para presentes, dispondo-se também a oferecer comodidade, agilidade e segurança fazendo entrega de seus produtos a domicílio.

De acordo com informações repassadas pela gerente de vendas da empresa, todo desenvolvimento das atividades da empresa tem se tornado possível, graças ao empenho e coesão da equipe de funcionários, que segundo ela, são vistos não como meros empregados, mas como colaborares e peças fundamentais em toda satisfação que tem sido concedida aos seus clientes. A equipe conta com oito colaboradores, incluindo a gerente geral, que é responsável por toda administração da empresa, tendo em vista que o proprietário não reside mais no local da empresa, tendo em sua funcionária uma pessoa de confiança, e com 
capacitação para gerenciamento de sua empresa, pois a mesma é formada em administração.

Quanto aos demais funcionários, dividem-se em quatro vendedores, um para atendimento no caixa e dois funcionários para controle e reposição de estoque. Todos os funcionários são orientados em suas funções pela gerente que atua diretamente com a equipe de vendas, treinando e acompanhando seus resultados através de reuniões quinzenais, que acontecem dentro da empresa e em horários fora do expediente oferecido aos clientes que é de segunda a sábado de 08:00 às 18:00 horas.

A empresa conta ainda com serviço de marketing feito através de redes sociais via internet, como Instagram, Facebook e Whatsapp, onde faz a divulgação de todos os produtos e serviços prestados. Para controle de vendas, estoque e fluxo de caixa, a empresa usa um sistema de gestão interligado a todos os setores, o que facilita uma melhor avaliação e adequação ao objetivo a que se propõe que é melhor atender seus clientes.

\subsection{Resultados da pesquisa}


É importante ressaltar que, por conta da pandemia, nosso artigo foi feito em caráter qualitativo, através de estudos científicos e baseado na descrição da gestora de equipe de vendas, a fim de atender as medidas preventivas de saúde.

De acordo com o estudo feito, a investigação segue os seguintes levantamentos no estudo de caso: uma boa variedade de produtos, demanda um estoque estruturado e isso foi visto na empresa com a definição de estoque mínimo, estoques de segurança, fornecedores de confiança e negociação de prazos ajustados ao movimento de caixa. A empresa não fica presa somente em volta às aulas, ela aproveita também as datas comemorativas, como: dia dos namorados, dia dos pais e das mães para ampliar o leque de produtos da sua empresa.

A qualidade dos produtos contribuiu para que a organização tivesse confiança ao estar adquirindo os produtos.

Segundo Miranda o conceito básico de qualidade é a ausência de defeitos e adequação ao uso (Miranda 1994). A excelência na qualidade é sempre o ponto mais 
visto pelos clientes, embora não seja a empresa que faz a produção, ela tem que observar a qualidade deles antes de ser colocado nas prateleiras, para que assim sendo vistos por seus clientes em bom estado, sejam reconhecidos esses cuidados com a qualidade dos produtos.

\section{CONCLUSÃO}

Com a realização deste estudo de caso, foi possível evidenciar a importância da gestão estratégica de vendas como forma de alavancar uma empresa para obtenção de bons resultados, tanto no âmbito financeiro, como no organizacional (equipe) e também comercial (clientes). Dentro dessa visão, percebe-se que um aspecto depende do outro para ter êxito.

Se há um bom desenvolvimento organizacional e operacional da equipe na empresa, consequentemente, os clientes que frequentam o estabelecimento ganharão confiança no serviço que é prestado, fidelizando-se e ajudando na captação de novos clientes. Acarretando assim, um bom resultado financeiro para a empresa. 
Isso ocorre, porque ela permite evidenciar o objetivo central da empresa, para atingir sua otimização, por meio de estratégias bem definidas que serão praticadas pela equipe, e ainda elevando o seu grau de produtividade. Porém, para que haja bons resultados, deve primordialmente, haver atuar nesse cenário um líder/gestor com forte presença e poder de persuasão, pois o fator motivacional por parte do gestor, conta muito para que a equipe busque cada vez mais alcançar metas e objetivos estabelecidos.

Consoante a isso, o estudo demonstrou que, os detalhes como esse mencionado, é um diferencial no mercado, pois um gestor forte e atuante, com uma equipe alinhada e capacitada em busca ao que foi proposto, gera bons frutos para a empresa como um todo.

E no que se refere a capacitação, evidenciou que ela está diretamente ligada ao alcance de resultados esperados. Uma vez que, é um fator que eleva o grau de produtividade e desempenho da equipe, aspecto que vai de encontro ao bom atendimento ao cliente, e em sequência a crescente demanda de novos clientes conquistados. Além disso, o bom desempenho do 
profissional atuante, depende do nível de interesse em descobrir a necessidade do seu cliente, bem como possuir habilidades como amor a profissão, disposição para o trabalho e capacidade de solucionar problemas rotineiros, e ainda a necessidade de alavancar profissionalmente. São pontos cruciais para bom desenvolvimento da empresa.

O processo de vendas, é um caminho que requer entendimento de vários aspectos relevantes para empresa, tais como o conhecimento do público frequentador e o que quer ser alcançado, um líder/gestor atuante que trace um plano bem definido e estruturado de vendas e motive sua equipe para tal designo, ofertando todo o suporte e capacitação, para então em conjunto, conquistar do que foi proposto. Por isso, constatou que fatores como Planejamento, Organização, Capacitação e a Motivação, são essenciais para que se alcance o objetivo de ter sucesso nas vendas.

$E$, nesse estudo de caso da empresa "Azul", observou-se e constatou-se que melhorias poderiam ser alcançadas no que diz respeito ao aumento do número de funcionários, para uma melhor distribuição do trabalho 
administrativo, para não sobrecarregar a gerente geral, podendo por esse motivo, estar deixando a desejar o serviço prestado, e sendo um obstáculo para conquista de avanços, que poderiam ser alcançados pela equipe de vendas, se fosse bem aplicada a gestão estratégica, com planejamento de metas, organização do trabalho, a capacitação da equipe para atuar com cordialidade, bem como a motivação frequente da equipe para o progresso da empresa.

Ademais, é um estudo que serve como fonte de informação e conhecimento para o meio científico e acadêmico, visando esclarecer a importância que uma boa gestão estratégica de vendas exerce em um mercado atual concorrido e progressivamente mutável. 
A GESTÃO ESTRATÉGICA DE VENDAS COMO FERRAMENTA DE SUCESSO AO DESEMPENHO ORGANIZACIONAL: estudo de caso de uma micro empresa

\section{REFERÊNCIAS}

BITTEL, Lester R. Supervisão Eficaz (tradução de Auriphebo Berrance Simões) 1ำ ed. São Paulo: McGrawHill do Brasil,1982

CASTRO, Luciano Thomé e. NEVES, Marcos Fava. Administração de Vendas: planejamento, estratégia e gestão. São Paulo: Atlas, 2012.

CHIAVENATO, Idalberto. Construção de talentos. Rio de Janeiro: Campus, 2002.

COBRA, Marcos. Administração de Vendas. 4º ed. São Paulo: Atlas, 1994.

FUTRELL, C. M. Vendas: Fundamentos e Novas Práticas de Gestão. 7º ed. São Paulo: Saraiva 2003.

KOTLER, Philip. Administração de Marketing: Análise, Planejamento, Implementação e Controle. São Paulo: Atlas, 1998.

LAS CASAS, Alexandre Luizzi. Administração de Marketing. São Paulo: Atlas, 2006.

LOPES, Graciela Montero Cunha. Como atender melhor seu cliente: curso. Brasília: Sebrae, 2017, p. 10. 
MELLO, C. H. P.; SILVA, C. E. S.; TURRIONI, J. B.; SOUZA, L. G. M. ISO 9001:2000. Sistemas de Gestão da Qualidade para Operações de Produção e Serviços. 3ª ed. São Paulo: Atlas, 2009.

MIRANDA, Roberto Lira. Qualidade total: Rompendo as Barreiras entre a Teoria e a Prática. $2^{2}$ ed. São Paulo: Makron Books, 1994.

ODA, Leonardo. Como melhorar suas vendas: curso. Brasília: Sebrae, 2017. 87p. Il., color, p. 26-28.

SLACK, N.; CHAMBERS, S.; JOHNSTON, R.; BETTS, A. Gerenciamento de operações e de processos: Princípios e Prática de Impacto Estratégico. 1ํed. São Paulo: Atlas, 2008.

THORN, Jeremy. Gerente de Vendas: O desafio da primeira gerência. São Paulo: Makron Books, 1992 p.3. 